\title{
Logistics models of modernization of distribution and transmission systems for the development of Ukraine as an exporter of green energy
}

\author{
Natalia Kovtun $^{1}$, and Nadiia Yushchenko ${ }^{2 *}$ \\ ${ }^{1}$ Taras Shevchenko National University of Kyiv, Department of Statistics and Demography, 90A, \\ Vasylkivska str., 03022 Kyiv, Ukraine \\ ${ }^{2}$ Khmelnytskyi National University, Department of Automated Systems and Modeling in Economics, \\ 11, Instytuts`ka str., 29016 Khmelnytskyi, Ukraine
}

\begin{abstract}
The article compares scientific facts and analyzes the prospects for the development of the export potential of Ukraine in the field of green energy against the background of an increase in the cost of silver used in the production of solar panels, and due to difficulties in meeting the increased demand for it by mining companies, as well as the expected reduction in the cost of thermonuclear energy due to the rapid implementation of the modified, thanks to advanced artificial intelligence systems, the design of the SPARC reactor. Economic and mathematical models for the regulation of stocks of material resources and equipment, including silver-containing ones, are proposed, which make it possible to study the invariants of managerial decisions and minimize costs. The main factors affecting the volume of formation of stocks are generalized, the types of costs associated with the management of stocks of material resources, the main types of economic and mathematical models for regulating stocks and computer programs available on the market that implement models and methods of supply management and stocks of material resources are systematized.
\end{abstract}

\section{Introduction}

So far, a world breakthrough in energy is expected since the creation of the first nuclear reactors, which is associated with the possibility of commercial use of nuclear fusion, which will provide the largest improvement in living standards in history, as well as make virtually every country food and energy independent. Indeed, having large-scale public and private funding, the SPARC reactor project, approved in 2020 at the Massachusetts Institute of Technology as promising to reduce the cost of thermonuclear energy, is rapidly improving thanks to new artificial intelligence technologies and the new technology can be implemented in a matter of years [1].

\footnotetext{
* Corresponding author: nadezhda15yu@gmail.com
} 
The International Energy Agency (IEA) predicts [2] that by 2025 renewable energy sources will supply one third of the world's electricity, thereby displacing coal from the first place and becoming the largest source of electricity in the world (Fig. 1).

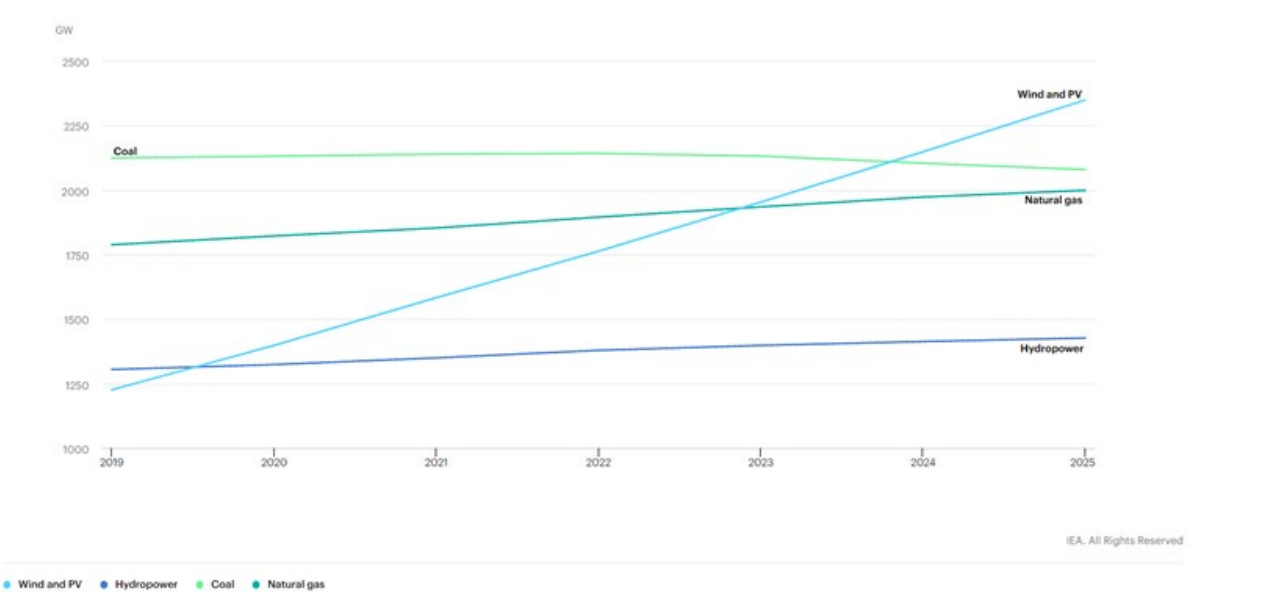

Fig. 1. Total installed power capacity by fuel and technology 2019-2025, main case [2].

Following global trends, realizing that energy efficiency and "green" energy is the key to a competitive economy, energy independence and the health of citizens [3] on sustainable development, "green" transformation, that is, in fact, given its high energy intensity, - on the new economy, and supports the ambitious program of the European Green Deal [4].

In an environment where more and more countries are considering the development of green energy and reducing the impact of the energy sector on the climate as a driver of renewal, a source for economic growth and job creation, from the point of view of the European Union, it may be a good goal for Ukraine to become an exporter of green energy. because the potential is there, the market is created. According to the Minister-Counselor of the European Commission, Thorsten Wollert, "this will be a good new direction and it may attract investments in the future" [5].

According to forecasts of the Danish investment Saxo Bank [6], due to the rapidly growing demand for industrial applications in 2021, there is a real shortage of silver in the market and this undermines political support for investment in solar energy under US President Joe Biden, "European Green Agreement", China's program to achieve carbon neutrality by 2060 and other initiatives.

In order to increase competitive advantages, business entities around the world are rapidly introducing new modern information and communication technologies and solutions for the creation of information resources and the use of digital technologies. The modern software market in the field of logistics is quite large and covers software products of various orientations and characteristics. Material and technical supply systems are being transformed in accordance with modern global trends based on the principles of systematic and logistic approaches, rationality, cost identification, transparency, trusting relationships, equality of approach and ensuring fair competition. There is a shift in the role of supply and material and technical support in enterprise management from solving tactical problems, serving its current needs to solving strategic [7], which increases the urgency of the problem of effective management of stocks of material resources. 


\section{Methods}

Many researchers work in the field of information technology development, methodology, theoretical and practical substantiation of the need for widespread use of adequate economic and mathematical models and methods in managerial decision-making procedures. The issues of the formation of factors influencing the sustainable development of the generating complex of the electric power industry are devoted to the studies of Dontsova O.I., Gibadullin A.A., Kerimova C.V., Morkovkin D.E. [8]. Belyaev N., Chudny V., Egorov A., Korovkin N. [9] are engaged in optimization of the conditions for modernization of heat power enterprises in modern conditions. Mayilyan L.D., Shogenov M.S., Zelentsov L.B. [10] are working on modeling the activities of organizations in the implementation of complex infrastructure projects. However, further formation and development requires economic and mathematical decision support tools for complex systems and capital-intensive projects, in particular, in the energy industry, which allows the subject of management to increase the efficiency of decision-making through modeling and automation of information procedures.

The main goal of this work is to analyze the current state and prospects of modernization of the fuel and energy complex and investments in renewable energy to achieve the Sustainable Development Goals in Ukraine, review, systematization and aspects of the classification of economic and mathematical tools for regulating supplies and inventories necessary for modernizing the energy system and development of Ukraine as an exporter of green energy.

\section{Results}

The costs associated with the operation of the inventory management system include costs associated with the formation of stocks, costs associated with holding inventory, losses due to lack of inventory or late delivery.

The economic regulation of stocks provides for the determination of a reasonable delivery lot, regulation of the frequency of deliveries, the best terms of shipment and receipt of materials.

In the theory of inventory management, there are the following types of models and corresponding methods for optimizing inventories based on the criterion of minimizing the costs associated with their storage and renewal, which make it possible to reasonably plan the need for material resources, warehouse space and mechanisms, [11, p. 176-184]:

- Wilson's model of determining a batch of an order, subject to uniform demand and the possibility of instant order fulfillment, which minimizes the costs associated with storing and maintaining the stock;

- one-product deterministic static model of optimal inventory management with a possible shortage. The main modifications of the deterministic single-product static model: prohibition of shortages, inability to store stock, replenishment of stocks is carried out instantly at certain intervals, replenishment of stocks is performed instantly, and the occurrence of a shortage is unacceptable;

- dynamic one-product deterministic model of inventory management and production output;

- one-product probabilistic static inventory management model;

- in the case of multi-product stocks, deterministic models are divided into three types: in which the interaction of products is clarified after delivery; with full combination of orders (full completing of batches in accordance with the technological package, etc.); with partial connection of orders. 
Numerous invariants of the above models have been developed and proved to be effective.

In practice, the limited resources, as well as the specific conditions of production and delivery, require adjustment of the batch size in comparison with the absolutely optimal, determined, for example, on the basis of the Wilson model [12, p. 214-215]. In particular, the company cannot fulfill large orders due to the limited working capital or the lack of open and closed storage facilities and storage tanks. Conversely, insignificant stocks may turn out to be unprofitable for the supplier due to frequent readjustments of equipment, which reduce its productivity and worsen the use of labor, or because the minimum shipment volume should not be less than the capacity of the container (wagon), since transport tariffs are calculated per container or wagon, regardless of the completeness of the load, and so on.

The economic and mathematical model of the problem of minimizing the costs associated with the formation and storage of stocks, taking into account the restrictions on the storage of several types of stocks, can be as follows.

Determine $q_{j}, j=\overline{1 ; k}$, ensuring minimum value

$$
\min : \quad C_{T}=\frac{R_{1}}{q_{1}} \sum_{j=1}^{k} c_{q_{j}}+\frac{q_{1} T}{2 R_{1}} \sum_{j=1}^{k} c_{1_{j}} R_{j},
$$

subject to restrictions

$$
\begin{gathered}
K=\frac{q_{1}}{R_{1}} \sum_{j=1}^{k} c_{j} R_{j} \leq K_{0}, \\
f=\frac{q_{1}}{R_{1}} \sum_{j=1}^{k} f_{j} R_{j} \leq f_{0}, \\
h=\sum_{j=1}^{k} h_{j}=\sum_{j=1}^{k}\left[\frac{R_{j}}{q_{j}}\right] \leq h_{0},
\end{gathered}
$$

where $q_{j}$ - batch size of the $j$-th resource (products), $j=\overline{1 ; k}$;

$\mathrm{C}_{\mathrm{T}}$ - costs associated with the formation and storage of stock to meet the needs of the enterprise in the planning period: $C_{T}=\sum_{j=1}^{k}\left(\frac{c_{q_{j}} R_{j}}{q_{j}}+\frac{c_{1_{j}} q_{j} T}{2}\right)$, but in the case of an assortment of demand, the batch sizes should be proportional to it

$$
q_{1}: q_{2}: \ldots: q_{k}=R_{1}: R_{2}: \ldots: R_{k}
$$

or

$$
\frac{q_{1}}{R_{1}}=\frac{q_{2}}{R_{2}}=\ldots=\frac{q_{k}}{R_{k}}
$$

therefore, the objective function takes the form (1), that is, it is transformed into a function of one variable $q_{1}$;

$R_{j}$ - demand for the $j$-th resource in the planning period;

$c_{q_{j}}$ - costs associated with organizing an order (production) of one batch of the $j$-th resource (products), regardless of the batch size, monetary units;

$c_{1_{j}}$ - costs of storing a unit of the $j$-th resource (products) per unit of time (proportional to the batch size), monetary units; 
$\mathrm{T}$ - duration of the planning period, days;

$\mathrm{K}$ - variable level of working capital, depending on $q$, and $\mathrm{K}_{0}-$ a given level of investment, monetary units;

$\mathrm{c}_{j}$ - unit cost of the $j$-th resource, monetary units;

$f_{j}$ - warehouse area occupied by the unit of the $j$-th resource, $\mathrm{m}^{2}$;

$h_{j}$ - the number of orders of batches of the $j$-th resource during the planning period;

(2) - limitation on the amount of available circulating assets, taking into account the range of demand; (3) - the limitation concerning the warehouse area available at the enterprise for storing stocks (taking into account the range of demand); square brackets in (4) represent the integer part of a number.

To determine the minimum of function (1), taking into account the assortment demand, it is necessary to determine the derivative $\frac{\partial C_{T}}{\partial q_{1}}$, equate it to zero, then

$$
q_{1}^{*}=R_{1} \sqrt{\frac{2 \sum_{j=1}^{k} c_{q_{j}}}{T \sum_{j=1}^{k} c_{1} R_{j}}}
$$

and from the formula (4)

$$
q_{j}=\frac{q_{1}}{R_{1}} R_{j}, \quad j=\overline{1 ; k} .
$$

To determine how justified the attraction of additional funds will be by reducing the costs of forming and storing the stock, the conditionally optimal batch size (6) is substituted into inequality (2). If it is fulfilled, solution (6) is final, since it fits into the limited amount of working capital $K_{0}$. In the opposite case, to determine the extremum of function (1), it is advisable to apply the method of Lagrange multipliers. In this case, an additional function is compiled $F=C_{T}+\left(K-K_{0}\right) \theta$, where $\theta$ is the variable Lagrange multiplier; the partial derivatives of the function $F$ with respect to $q_{1}$ and $\theta$ are determined, are equated to zero. From the equation $\frac{\partial F}{\partial \theta}=0$ is determined by $q_{1}$; from the equation $\frac{\partial F}{\partial q_{1}}=0$ is determined by $\theta$. As a result of simple transformations, $q_{1}$ can be expressed through $\theta$. It was reported [13] that with small increases in working capital $\Delta K_{0}$, the conditionally optimal plan (6) improves, providing a cost reduction $-\Delta C_{T}$ proportional to $\Delta K_{0}$ with a proportionality coefficient $\theta: \Delta C_{T}=-\theta \Delta K_{0}$.

Thus, $\theta$ turns into an estimate of the monetary units of current assets: with an increase in circulating assets by 1 monetary unit, costs will be reduced by $\theta$ monetary units.

Similarly, on the basis of the Lagrange multiplier method and an auxiliary function $F=C_{T}+\left(f-f_{0}\right) \theta$, the problem of optimizing reserves with a limitation in areas is solved.

The most essential in order management is the limitation (4) concerning the quantity, and hence the size of orders. Taking into account (4), the objective function will have the form

$$
C_{T}=\sum_{j=1}^{k}\left(c_{q_{j}} h_{j}+\frac{c_{1_{j}} T R_{j}}{2} \cdot \frac{1}{h_{j}}\right) \rightarrow \min
$$


In this case, the enumeration of a number of values $h_{j}$ satisfying condition (4), and the choice of them conditionally optimal according to criterion (7) is inevitable, since differentiation of function (7) with respect to $h_{j}$ is inadmissible due to the integer value of $h_{j}$.

When taking into account several restrictions at the same time, it should be borne in mind that (2) and (3) limit the lot size from above, and (4) - from below. In the first case, the batch size is selected that satisfies the most stringent condition; in the second, the problem has a solution under the condition of the existence of such batch sizes that satisfy two-sided inequalities.

Optimization of stocks using the methods of mathematical analysis according to the criterion of minimizing the total amount of costs for their storage and renewal makes it possible to reasonably plan the need for material resources, storage sites, storage areas and mechanisms.

\section{Discussion}

Comparative analysis [14] of software tools available on the market for material flow management by their functionality: procurement / purchasing, warehouse operations, sales and marketing suggests that the most extensive opportunities are provided by BEST (Business Environment Strategic Toolkit), Parus, Galaktika, Axapta packages and Axapta Retail. For use by accountants-analysts, the program "1C: Trade Management" may be appropriate, which has ample opportunities for preparing all the necessary documents, managing the movement of goods and pricing, accepting orders and monitoring their implementation, optimizing warehouse stocks, analyzing goods turnover, planning purchases and deliveries.

The overwhelming majority of software products offered on the market are accounting and require adaptation to specific business conditions. Some have a built-in programming language that allows you to create your own applications. They are expensive and targeted at large corporate structures. However, inventory management problems can be solved by universal means, in particular, MS Excel or MathCAD can be used for optimization problems, for problems using the methods of probability theory and mathematical statistics - Statistica, Gretl and other statistical software products.

\section{References}

1. Saxo Group. (2020). Revolutionary fusion design catapults humanity into energy abundance. https://www.home.saxo

2. International Energy Agency. (2020). Renewables 2020. Analysis and forecast to 2025. https://www.iea.org/reports/renewables-2020

3. Cabinet of Ministers of Ukraine. (2021, 29 January). Energy efficiency and green energy are key to a competitive economy and energy independence of communities. https://www.kmu.gov.ua

4. Ministry of Environment Protection and Natural Resources of Ukraine. (2020). Concept of Ukraine's "green" energy transition until 2050. https://mepr.gov.ua/news/34424.html

5. Analytical Center DiXi Group. (2021). Discussion with ambassadors: decarbonization, COP26, green economy. The visit was organized by the British Embassy in cooperation with the DiXi Group Analytical Center. https://dixigroup.org 
6. Saxo Group. (2020). Sun shines on silver, which sizzles on solar panel demand. https://www.home.saxo/content/articles/outrageous-predictions/sun-shines-on-silverwhich-sizzles-on-solar-panel-demand-08122020

7. Kearney, A. T. (2007). Creating value through strategic supply management. 2004 Assessment off excellence in procurement. https://managementtools.blogspot.com/2007/04/creating-value-through-strategic-supply.html

8. Morkovkin, D.E., Kerimova, C.V., Dontsova, O.I. \& Gibadullin, A.A. (2019). The formation of factors affecting the sustainable development of the generating complex of the electric power industry. Journal of Physics: Conference Series, 1399(3).

9. Belyaev, N., Egorov, A., Korovkin, N. \& Chudny, V. (2019). Allowance for capacity adequacy criterion in optimizing the prospective structure of electric power system. E3S Web of Conferences, 139.

10. Zelentsov, L.B., Mayilyan, L.D. \& Shogenov, M.S. (2019). Organizational and technological simulation of the construction organization activity in the complex infrastructure projects implementation. IOP Conference Series: Materials Science and Engineering, 698(7).

11. Yushchenko, N.L. (2016). Economic and mathematical models in management and economics. Chernihiv : Chernihiv. nat. technologist University.

12. Sakovich, V.A. (1984). Research of operations (deterministic methods and models). Minsk : Higher School.

13. Kulish, S.A., Valovelskaya, S.N. \& Rabinovich, I.A. (1974). Mathematical methods in planning material and technical supply. Kyiv : Higher School.

14. Yushchenko, N.L. \& Vorokh, M.M. (2016). Comparative analysis of software products that implement models and methods of supply management and inventories. Problems and prospects of economics and management, 1 (5), 74-87. 